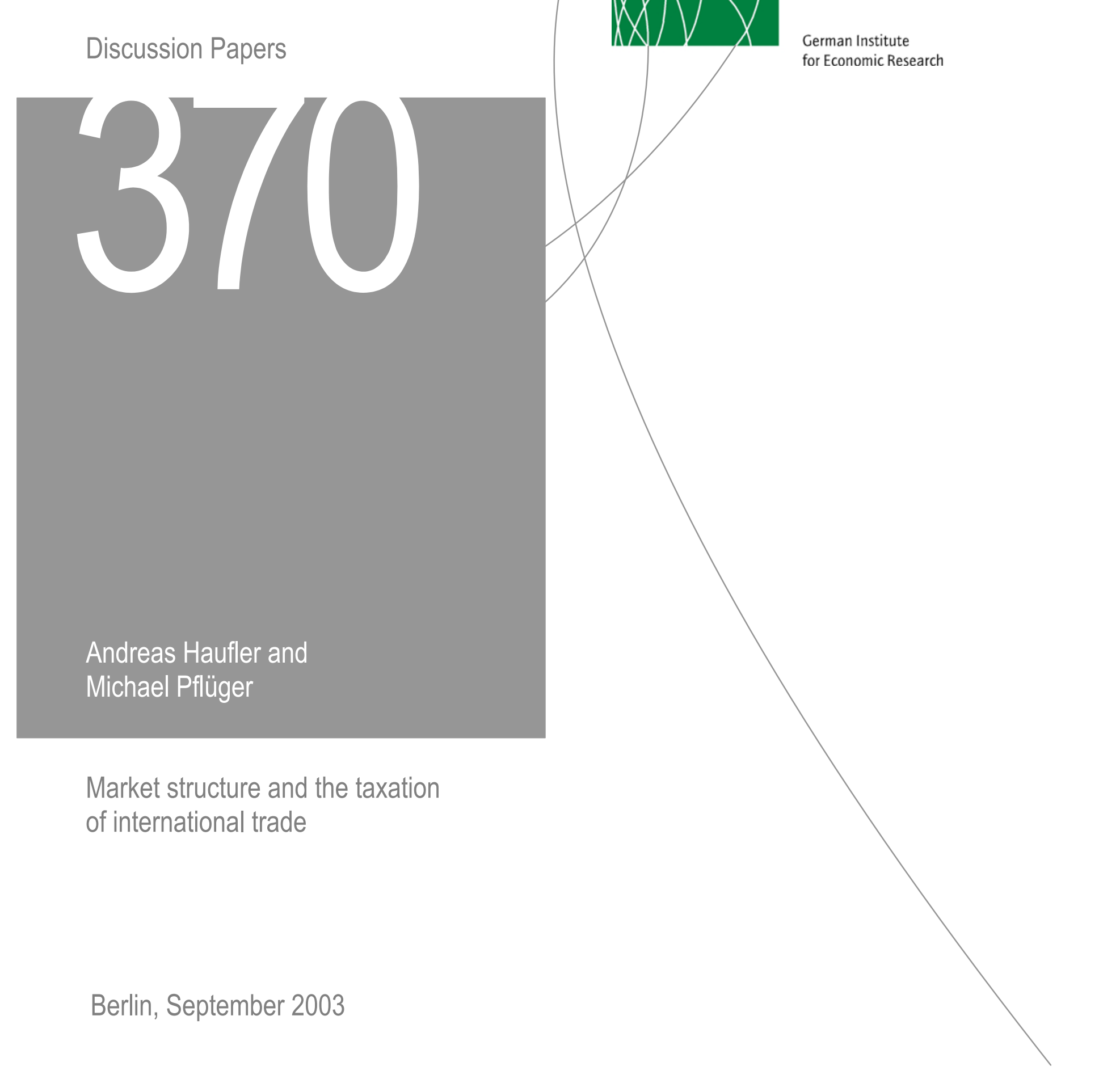


Opinions expressed in this paper are those of the author and do not necessarily reflect views of the Institute.

DIW Berlin

German Institute

for Economic Research

Königin-Luise-Str. 5

14195 Berlin,

Germany

Phone +49-30-897 89-0

Fax $\quad+49-30-89789-200$

www.diw.de

ISSN 1619-4535 


\title{
Market structure and the taxation of international trade *
}

\author{
Andreas Haufler \\ Michael Pflüger \\ University of Munich \\ DIW Berlin and IZA
}

September 2003

\begin{abstract}
The paper compares non-cooperative commodity taxation under the destination and origin principles under a variety of different assumptions about market structure. We consider a model of international duopoly with either quantity or price competition of firms and either segmented or integrated markets, and a monopolistic competition model with mobile firms. In each setting the international spillovers of tax policy are isolated and evaluated at the Pareto efficient tax rate. The sign of the net spillover, and thus the direction that commodity tax competition will take, depends critically on whether lump-sum taxes are available or commodity taxes must be used to finance the government budget.

Keywords: tax competition, market imperfections, international trade JEL-Classification: F12, H21, H87
\end{abstract}

*Paper presented at the annual conferences of the Royal Economic Society in Warwick, the European Economic Association in Stockholm, the International Institute of Public Finance in Prague, and at seminars in Berlin and Zürich. We thank seminar participants, in particular Rainald Borck, Lucas Bretschger, Wilhelm Kohler, Phillip Schröder and Bengt-Arne Wickstroem for helpful comments. 


\section{Introduction}

The recent research on the taxation of international commerce has much in common with, and owes a lot to, analyses of trade policy with imperfect competition in goods markets. Its policy importance arises from the fact that, over the past decades, the role of general consumption taxes as a means of financing the government budget has increased substantially. ${ }^{1}$ The ongoing process of international economic integration has put severe limits on the enforceability of the destination principle, the yet dominant mode of international commodity taxation which levies taxes in the country of consumption and relies on border tax adjustments. ${ }^{2}$ For these reasons the alternative of levying commodity taxes in the country of production (origin principle) has become increasingly relevant in policy discussions. This applies in particular in the European Union (Keen and Smith, 1996) and in other integrating regions, such as the Community of Independent States, but similar issues also arise for the taxation of interstate commerce in the United States (Mikesell, 2000).

At the same time the conventional efficiency arguments, which favor the destination over the origin principle under conditions of perfect competition, have also been challenged. The recognition that competition in goods markets may be far from perfect has led some researchers to conclude that the taxation of international trade in the country of production may, in fact, be superior from a theoretical point of view (Keen and Lahiri, 1998). However, in a number of recent papers it has also been shown that this conclusion is not robust and similar ambiguities have arisen as in trade policy analyses under imperfect competition. Since the underlying models are the same, this cannot come as a surprise. Policymakers face the question of what then to conclude from these exercises. In new trade theory, much clarity was gained by setting up more comprehen-

\footnotetext{
${ }^{1}$ In the OECD average, taxes on total consumption accounted for $11.9 \%$ of total government revenues (incl. social security contributions) in 1965, and this share has risen to $17.9 \%$ in 1998 (OECD 2000). This development is closely linked to the widespread adoption of the value-added tax (VAT), which is now the primary commodity tax in more than 100 countries worldwide (Cnossen, 1998).

${ }^{2}$ In the European Union, there is first empirical evidence that VAT evasion has grown following the changes in VAT administration in the internal market (Nam et al., 2001). In North America, the main issue is the growth of electronic commerce, which has been shown to react very sensitively to the level of sales taxation in the residence state of the consumer (Goolsbee, 2000).
} 
sive models which allowed to compare results for a wide range of assumptions about market structure and conduct of firms (Eaton and Grossman, 1986; Markusen and Venables, 1988; Cheng, 1988; Helpman and Krugman, 1989; Brander, 1995).

The present paper is in the spirit of these works. By building our analysis on the two workhorses of new trade theory, the models of international oligopoly and monopolistic competition, we are able to capture aspects of market structure and conduct which, judging from trade policy analysis under imperfect competition, can be expected to be of crucial importance for the comparison of international tax regimes. These are $(i)$ the nature of strategic interaction between firms, notably the distinction between decision variables that are strategic substitutes or strategic complements, $(i i)$ the distinction between segmented and integrated markets, (iii) the degree of substitutability of goods in demand, and $(i v)$ the role of international mobility of firms.

In order to carry out such a comprehensive study of the regimes of commodity taxation in a transparent way, we apply two strategic devices. The first is to make some fundamental assumptions that keep the models tractable and permit to compare the results of different models in similar scenarios. Therefore, we focus on non-cooperative tax policies ${ }^{3}$ and assume throughout the analysis that the (two) competing countries are identical in all respects. Moreover, we work with simple functional forms. To tie our analysis to previous studies of trade policy we use those specifications that are standard in studying oligopolistic markets (symmetric, quadratic, quasi-linear utility) and monopolistic markets (CES utility and iceberg transport costs). Clearly, adopting these assumptions implies some loss of generality.

Our second strategic device is to develop a general welfare-theoretic framework and a methodological strategy centering around the concept of the indirect utility function. Apart from being a flexible tool to incorporate alternative market structures and model specifications ${ }^{4}$, this approach allows us to isolate, classify and study the various tax spillovers (tax externalities) that a tax change in one country has on the welfare of

\footnotetext{
${ }^{3}$ Present international arrangements leave countries almost full autonomy to set general commodity tax rates at the national level. International coordination occurs only in the European Union, and even there the current minimum VAT rate of $15 \%$ is binding only for a single member state (Luxembourg).

${ }^{4}$ See e.g. the syntheses of trade policy and regional integration in Markusen and Venables (1988), Helpman and Krugman (1989) and Baldwin and Venables (1995).
} 
others. The simplicity of the underlying models allows us to determine the cooperative (Pareto efficient) tax rate as well as the non-cooperatively chosen tax rates for all cases under consideration. More importantly, evaluating the various spillovers at the cooperative tax rate allows to explain why previous studies have obtained conflicting results, and to clarify the nature of results in more general settings. In particular, we incorporate a public good and highlight the crucial role that the existence of a government revenue motive plays for the evaluation of tax spillovers, and for the choice between the destination and origin regimes.

The paper is set up as follows. Section 2 briefly reviews the existing literature on international commodity taxation. Section 3 develops the general framework in which our analysis is carried out. Section 4 discusses the benchmark case of perfect competition in all goods markets. Section 5 compares destination- versus origin-based commodity taxation in an international duopoly model when firms compete over quantities. Section 6 analyses the same framework with price competition of firms. Section 7 introduces a model of monopolistic competition and international firm mobility. Section 8 compares the results obtained in the different settings and Section 9 concludes.

\section{A brief review of the literature}

The earlier literature on commodity tax competition has assumed that goods markets are perfectly competitive. In a setting where cross-border purchases by consumers are effectively taxed in the country of origin, Mintz and Tulkens (1986) isolate two fundamental spillovers of tax policy, which affects both consumer prices and tax revenues in the foreign country. For the case of revenue-maximizing governments, Kanbur and Keen (1993) demonstrate that the externality on foreign tax revenues dominates, and commodity taxes will be set inefficiently low under the origin principle. Since there is no comparable downward pressure on tax rates under the destination principle, this finding constitutes one main efficiency argument in favour of the destination principle under conditions of perfect competition. Lockwood (1993) shows, however, that the comparison between the two tax regimes is less clear-cut when additional terms of trade effects enter the analysis. The literature dealing with perfectly competitive product markets is systematically summarised in Lockwood (2001, sections 2 and 3). 
More recently, there have been a number of contributions analyzing the effects of international commodity taxes under imperfectly competitive market structures. One set of papers compares the destination and origin principles in a model of international duopoly where two firms, one in each country, produce a homogeneous good. In this setting, Keen and Lahiri (1998) show for a variety of cases under both coordinated and non-coordinated tax setting that the origin principle is likely to dominate the destination principle from a global efficiency perspective. One particularly noteworthy result of their analysis (Proposition 6) is that when countries are identical, non-cooperative taxation under the destination principle causes efficiency losses, whereas tax competition under the origin principle yields the first best. Haufler, Schjelderup and Stähler (2002) have introduced transport costs and market segmentation into this model and show that the welfare comparison between the two tax regimes becomes ambiguous in this case. For low levels of transport costs the origin principle continues to dominate, but this ranking is turned around in favor of the destination principle when transport costs become sufficiently high.

A different strand in the literature combines imperfect substitutability of goods with profit-making firms. Lockwood (2001, sec. 4 and 6) assumes that firms can export into foreign markets, but they cannot relocate abroad. In this model taxes levied under either the destination or the origin principle create international spillovers on the profits of foreign firms, and the welfare comparison of Nash equilibria under the two regimes is ambiguous. Haufler and Pflüger (2003) use a model of monopolistic competition that incorporates transport costs and allows for international mobility of firms, but does not incorporate a public good. A striking result of this analysis is that non-cooperative tax policy under the destination principle achieves the first best, because the tax spillovers on foreign rent income and foreign consumer prices exactly offset each other. Hence, in the absence of a government revenue motive the monopolistic competition model with firm mobility and the duopoly analysis of Keen and Lahiri (1998) have directly conflicting implications for the choice between the destination and origin regimes when tax rates are set non-cooperatively. ${ }^{5}$

\footnotetext{
${ }^{5} \mathrm{~A}$ still different approach is taken by Haufler and Schjelderup (2003), who compare the stability of collusive agreements in a repeated game setting under the destination and origin principles. Their analysis yields a (qualified) conclusion in favor of the origin principle, in the sense that this tax regime
} 


\section{A general welfare-theoretic framework}

\section{Preferences and consumption}

In order to capture and illustrate the variety of effects that commodity taxes can have in settings of imperfect competition, a framework is needed that is general and simple at the same time. This section presents our choice of such a model. We consider a world which consists of two symmetric countries, home and foreign, where the foreign country is denoted by an asterisk $\left(^{*}\right)$. The following model description is for the home economy only, all expressions for the foreign country are analogous.

There are $n$ identical consumers in the domestic economy. Each consumer owns one unit of capital and supplies one unit of labour without loss of utility. She derives (direct) utility $u($.$) from the consumption of three private goods, x, y$ and $z$, and from the consumption of a public good, $g$. Good $z$ is the numeraire, which is assumed to be untaxed. Goods $x$ and $y$ are taxed either according to the destination principle (henceforth: DP) or according to the origin principle (henceforth: OP). ${ }^{6}$ It is convenient to perform the analysis not in terms of the direct utility of the representative consumer, but in terms of her indirect utility function, $v$. Indirect utility depends on the vector of consumer prices in the home country $q=\left(q_{x}, q_{y}, 1\right)$, the value of the consumer's endowment (or income) $e$, and the level of public good provision $g$ :

$$
v(q, e, g) \equiv u[x(q, e), y(q, e), z(q, e), g]
$$

Here $x(),. y($.$) and z($.$) are the consumer's Marshallian demand functions. In the fol-$ lowing we place some restrictions on the consumer's direct utility. First, utility is a quasi-linear function of private goods with the numeraire entering linearly and where all goods are assumed to be consumed (different yet standard quasi-linear specifications shall be used and explained as we go along). The marginal utility of income is then unity and the demand for $x$ and $y$ is independent of the consumer's income. Second, utility is additively separable between private goods and the public good and the marginal

is more likely to destabilise socially undesirable cartels.

${ }^{6}$ If all goods (including the numeraire) are taxed at the same rate, the destination and origin regimes are equivalent under rather general conditions, including the case of imperfect competition. See Lockwood, de Meza and Myles (1994). 
utility from public goods consumption is assumed to be constant, $\partial v / \partial g=\delta \geq 1 .^{7}$ Totally differentiating the indirect utility function, using Roy's identity, and dividing by the marginal utility of income, $\partial v / \partial e=1$, we then obtain

$$
d v=-x(q) d q_{x}-y(q) d q_{y}+d e+\delta d g
$$

The representative consumer receives income from her endowments of one unit of labour and capital. Denoting the wage rate in the home economy by $w$, the return to capital by $r$ and allowing for the possibility of lump-sum taxes $h$ gives the per-capita budget constraint in the home country

$$
e=w+r-h
$$

\section{Production}

The untaxed numeraire good, $z$, is produced in perfectly competitive markets using labour as the only input. Quantities are chosen such that it takes one unit of labour to produce one unit of the numeraire. The numeraire good is tradable without cost and is produced in both countries. These assumptions fix wages in both countries at unity ${ }^{8}$

$$
w=w^{*}=1
$$

The focus of our analysis is on the imperfectly competitive sector. Different market structures are allowed for the taxed goods $x$ and $y$, which will be described in detail in the subsequent sections.

\section{Government}

We denote by $t_{k}, k \in\{d, o\}$ the common commodity tax rate on the non-numeraire goods, which is levied either according to the destination principle $(k=d)$ or according to the origin principle $(k=o)$. The home country's per capita tax bases under the two

\footnotetext{
${ }^{7}$ This assumption is needed to keep the analysis tractable when the marginal source of tax revenues is endogenously determined in the model (see below). Alternatively, the marginal utility from public good consumption can be allowed to vary with the level of $g$ when the marginal source of tax revenues is determined outside the model. The latter approach is taken, for example, by Keen and Lahiri (1998).

${ }^{8}$ An alternative modelling strategy with similar implications is to choose labour as the numeraire and to assume that labour is perfectly mobile across countries. See Lockwood (2001).
} 
regimes are denoted by $b_{k}$. Under the DP the tax base is domestic consumption per capita, whereas under the OP it is domestic per-capita production. The public good represents an alternative use of the private numeraire good and its cost of production is unity. Moreover, it is of the quasi-private type, i.e., there are no scale economies in providing it to a large number of consumers. ${ }^{9}$ The government budget constraint is then

$$
g_{k}=t_{k} b_{k}+h \quad \forall k \in\{d, o\}
$$

This formulation allows for two different cases. In the first, the lump-sum tax $h$ is available. One interpretation of this case that is frequently used in the trade literature is that no public good exists and all commodity tax revenues are redistributed to the consumer lump sum. An equivalent interpretation, which will be employed here, is that the valuation of the public good by consumers is $\delta=1$, so that the public good is effectively a perfect substitute for private income [cf. eq. (2)]. In the second case $h=0$ and the public good must entirely be financed from the proceeds of commodity taxation. Since the commodity taxes are distortive, this case implies that the consumer's valuation of the public good must exceed unity, and be sufficiently high to induce positive commodity tax rates. In the following we therefore distinguish between the case of lump-sum finance, $\delta=1$, and the case of commodity tax finance, $\delta>\bar{\delta} \geq 1$, where $\bar{\delta}$ denotes the consumer's valuation of the public good that induces a zero commodity $\operatorname{tax}^{10}$

\section{Cooperative and non-cooperative tax choices}

The different elements of the representative consumer's indirect utility function (the consumer price index, income and the level of public good provision) can all be affected by commodity taxes. Hence, the indirect utility can be written as $v\left(t_{k}, t_{k}^{*}\right)$, where $t_{k}^{*}$ is the tax rate chosen by the foreign government. We shall work with a simple utilitarian welfare criterion so that the social planner maximises the sum of utilities, $v+v^{*}{ }^{11}$ The

\footnotetext{
${ }^{9}$ This formulation is frequently used in related models since it simplifies the notation without changing any of the results. See, e.g. Bucovetsky (1991) and Wilson (1991).

${ }^{10}$ In the analysis below we determine the critical value $\bar{\delta}$ which induces a zero tax rate under cooperative tax policy. However, the reader should be aware that this is only a necessary condition, since non-cooperatively chosen tax rates are below the cooperative tax in several of the cases analysed.

${ }^{11}$ This is a valid welfare criterion since the marginal utilities of income are equalised (equal to one)
} 
cooperative choice of tax rates $\left(t_{c}, t_{c}^{*}\right)$ then follows from the two first-order conditions

$$
\frac{d v}{d t_{k}}+\frac{d v^{*}}{d t_{k}}=0 \quad \text { and } \quad \frac{d v}{d t_{k}^{*}}+\frac{d v^{*}}{d t_{k}^{*}}=0 .
$$

Since the countries are symmetric, these two conditions must yield identical conditions for the cooperative (Pareto efficient) tax, and it is sufficient to look at one of them. Moreover, due to symmetry, the two countries can be treated as a single large economy in the cooperative case, making the distinction between destination and origin taxation irrelevant. Hence, the cooperative tax rate can either be derived under the destination or under the origin regime. In general, it is easier to derive the optimal cooperative tax rate under the destination regime, and this is how we will proceed below.

In the non-cooperative case, each government maximises the indirect utility of its own representative consumer. Accordingly, the non-cooperative tax rates follow from

$$
\frac{d v}{d t_{k}}=0 \quad \text { and } \quad \frac{d v^{*}}{d t_{k}^{*}}=0 \quad \forall k \in\{d, o\} .
$$

Again, the non-cooperative tax rates $\left(t_{d}, t_{d}^{*}\right)$ under the DP and $\left(t_{o}, t_{o}^{*}\right)$ under the OP can be derived from one of these conditions, as the two countries will choose the same tax rate in the non-cooperative equilibrium.

In contrast to the two independent governments, the social planner's choice of tax rates internalises all possible externalities between the two countries. It follows from the comparison of conditions (6) and (7) that any discrepancy between the cooperative and the non-cooperative choice of tax rates must lead to spillover terms $d v^{*} / d t_{k}$ and $d v / d t_{k}^{*}$. To determine whether non-cooperative tax rates are above or below the cooperative level, the spillovers must be evaluated at the cooperative tax rate. This property will play a central role in the subsequent analysis.

The domestic welfare effects of a change in the home country's tax rate are obtained by substituting (3) and (5) in (2), differentiating with respect to $t_{k}$ and using (4). This gives $^{12}$

$$
\frac{d v}{d t_{k}}=-\left[x(q) \frac{d q_{x}}{d t_{k}}+y(q) \frac{d q_{y}}{d t_{k}}\right]+\frac{d r}{d t_{k}}+\delta\left(b_{k}+t_{k} \frac{d b_{k}}{d t_{k}}\right) \quad \forall k \in\{d, o\} .
$$

with quasi-linear utility functions in both countries.

${ }^{12}$ Note that the terms involving the lump-sum tax $h$ do not affect the net welfare changes in (8) for either of the two cases of financing the government budget. This result follows trivially if $h=0$. If $h>0$ then $\delta=1$ from our above discussion, and the loss in private income is fully offset by the utility gain from the public good. 
The externalities on the foreign country's welfare are analogously derived as

$$
\frac{d v^{*}}{d t_{k}}=-\left[x^{*}\left(q^{*}\right) \frac{d q_{x}^{*}}{d t_{k}}+y^{*}\left(q^{*}\right) \frac{d q_{y}^{*}}{d t_{k}}\right]+\frac{d r^{*}}{d t_{k}}+\delta t_{k}^{*} \frac{d b_{k}^{*}}{d t_{k}} \quad \forall k \in\{d, o\}
$$

Three possible externalities can be distinguished in (9), when governments choose their tax rates independently (cf. Lockwood, 2001). The bracketed first term on the RHS of (9) represents a private consumption spillover, the second term is a rent spillover and the third term is a public consumption spillover. The market forms that we consider in the following give rise to a variety of combinations of these three basic externalities, and the net spillovers will generally differ under the destination and origin regimes of commodity taxation. ${ }^{13}$

\section{The benchmark: perfect competition}

The case where all goods markets are perfectly competitive, and production in the taxed sector takes place with constant returns to scale, is discussed in detail by Lockwood (2001, sections 2 and 3). Our treatment can thus be brief and serves primarily as a reference point for our discussion in the following sections. To facilitate this comparison, it proves convenient to introduce the same assumptions about preferences and production technologies that will be used in the duopoly framework below. We assume that production of each good uses labour inputs only. With perfect competition this implies that capital (profit) income in (3) is $r=0$. This fixes the producer prices for $x$ and $y$ at their unit labour costs, denoted by $c_{i}, i \in\{x, y\}$. The home country produces goods $x$ and $z$ while the foreign country produces $y$ and $z$. Commodity taxes levied on $x$ and $y$ (in home and foreign, respectively) are modelled as specific taxes. The per capita tax base in the home country is $b_{d}=x+y$ in the destination regime and $b_{o}=x+x^{*}$ in the origin regime.

Preferences are represented by a symmetric, quadratic, quasi-linear utility function which is widely used in industrial organisation and trade (e.g. Singh and Vives, 1984;

\footnotetext{
${ }^{13}$ The signs of the spillovers in the different models are summarized in Table 1. The reader may find it convenient to refer to this table as the analysis proceeds, but an explicit discussion of the table is deferred to Section 8 .
} 
Markusen and Venables, 1988). This gives, for the home consumer

$$
u(x, y, z)=\alpha(x+y)-\frac{\beta}{2}\left(x^{2}+y^{2}\right)-\gamma x y+z, \quad \beta \geq \gamma,
$$

where $(\beta / \gamma)$ measures the degree of heterogeneity between the two taxed goods and $\beta=\gamma$ represents the special case of homogeneous goods. In the following, we will generally assume that goods $x$ and $y$ are substitutes $(\gamma>0)$. Utility maximization yields linear inverse demand curves

$$
q_{x}=\alpha-\beta x-\gamma y, \quad q_{y}=\alpha-\beta y-\gamma x .
$$

Inverting (10) gives demands for goods $x$ and $y$ in the home country

$$
x=\frac{\alpha}{\beta+\gamma}-\frac{\beta q_{x}}{\left(\beta^{2}-\gamma^{2}\right)}+\frac{\gamma q_{y}}{\left(\beta^{2}-\gamma^{2}\right)}, \quad y=\frac{\alpha}{\beta+\gamma}-\frac{\beta q_{y}}{\left(\beta^{2}-\gamma^{2}\right)}+\frac{\gamma q_{x}}{\left(\beta^{2}-\gamma^{2}\right)} .
$$

As explained before, it is simplest to derive the cooperative tax rate under the destination regime. Consumer prices in the home and the foreign country are then

$$
q_{i}=c_{i}+t_{d}, \quad q_{i}^{*}=c_{i}+t_{d}^{*}, \quad \forall i \in\{x, y\}
$$

From (12) and (11), and noting that profit income in both countries is zero, we can calculate all terms in (8)-(9). Using the results in (6) and solving for the cooperative tax rate under perfect competition (superscript $P$ ) gives:

$$
t_{c}^{P}=\frac{(\delta-1)(x+y)(\beta+\gamma)}{2 \delta} \geq 0 .
$$

Eq. (13) has a familiar interpretation. With lump-sum finance $(\delta=1)$ the optimal cooperative tax rate is zero, as any non-zero tax distorts consumers' choices between the taxed goods and the untaxed numeraire. Hence the threshold value for the consumer's valuation of the public good is $\bar{\delta}^{P}=1$ in this case, and any level of $\delta>1$ is consistent with a positive commodity tax rate.

The spillovers under the DP are evaluated from (9), using (12) and (11). This gives

$$
\frac{d v^{*}}{d t_{d}}=0
$$

Eq. (14) reproduces the benchmark result that non-cooperative tax policy under the destination principle is Pareto efficient when perfect competition prevails in goods markets and producer prices are fixed (cf. Lockwood, 2001, Proposition 1). The reason 
is apparent from (12): a destination-based tax increase in one country does not affect consumer prices abroad, and hence does not impact on foreign consumption plans and the foreign tax base. ${ }^{14}$

Under the origin principle, the consumer prices in home and foreign are

$$
q_{x}=q_{x}^{*}=c_{x}+t_{o}, \quad q_{y}=q_{y}^{*}=c_{y}+t_{o}^{*}
$$

Recalling that good $x$ is produced by home and good $y$ by foreign, the foreign consumer price of good $x$ is now directly affected by a domestic tax increase. Using (15) and (11) in (9), and evaluating at the cooperative tax rate (13), the tax spillovers on foreign welfare are

$$
\frac{d v^{*}}{d t_{o}}=-x^{*}+\frac{(\delta-1)(x+y) \gamma}{(\beta-\gamma)} .
$$

The first term in (16) is a negative consumer price spillover on the foreign country. The second term is a public consumption spillover, which must be evaluated at the cooperative tax rate. If lump-sum taxes exist $(\delta=1)$ the cooperative tax rate and the public consumption spillover are zero and the net externality is negative. ${ }^{15}$ If commodity tax revenues must be positive $(\delta>1)$, then the consumer price and tax base spillovers are counteracting. This ambiguity is already present in the seminal contribution by Mintz and Tulkens (1986). Eq. (16) shows the conditions under which the tax base externality dominates the private consumption spillover: $(i)$ if governments behave as revenue-maximisers $(\delta \rightarrow \infty)$, only the public consumption externality matters and taxes will be unambiguously set 'too low' (cf. Kanbur and Keen, 1993); (ii) if goods $x$ and $y$ are close substitutes $(\beta \rightarrow \gamma)$ the tax-induced increase in foreign consumer prices becomes negligible, relative to the changes in the foreign tax base (cf. Lockwood, 2001, Proposition 2). ${ }^{16}$ We summarise our findings in this section in

\footnotetext{
${ }^{14}$ Note, however, that the assumption of fixed producer prices is critical for this result. If producer prices are variable, a tax change under the DP will generally cause producer price spillovers (termsof-trade effects) in the foreign country (see Lockwood, 1993; 2002, section 3).

${ }^{15}$ The consumer price spillover under the OP will also disappear when the two countries are symmetric and produce the same goods. In this case there will be no trade and $x^{*}=0$.

${ }^{16}$ Lockwood (2001, Prop. 2) also considers the case where $x$ and $y$ are complements; this corresponds to $\gamma<0$ in our setting. Eq. (16) shows that the tax base externality then changes its sign, and noncooperative taxes under the OP unambiguously exceed their Pareto efficient levels.
} 
Proposition 1: With perfectly competitive goods markets and fixed producer prices, the following holds [Lockwood, 2001, Propositions 1 and 2]:

(a) under the destination principle, tax rates in the non-cooperative equilibrium are at their Pareto efficient level for any level of $\delta$;

(b) under the origin principle, tax rates in the non-cooperative equilibrium (i) are above their Pareto efficient level when lump-sum taxes exist $(\delta=1)$; (ii) are below their Pareto efficient level when governments behave as revenue maximisers, or when $\delta>1$ and the taxed goods are close substitutes $(\beta \rightarrow \gamma)$.

\section{International duopoly with quantity competition}

With imperfect competition rent spillovers are encountered in addition to consumer price and public consumption spillovers. Moreover, governments now have a motive to correct the production distortion by means of a subsidy, and the optimal coordinated tax rate is no longer zero in the presence of lump-sum taxes. From analyses of strategic trade policy, it is well known that the results of policy interventions are sensitive to the assumptions whether firms use quantities (Cournot case) or prices (Bertrand case) as strategic variables (Eaton and Grossman, 1986), whether markets are integrated or segmented (Markusen and Venables, 1988), and whether goods are homogeneous or heterogeneous. To compare the different cases, this section analyses quantity competition between firms and the next section takes up price competition. Under both specifications of firm behavior we allow for heterogeneous and homogeneous goods, and we consider segmented and integrated markets.

The demand structure of our heterogeneous duopoly model is the same as in the previous section and leads to the inverse demand functions given in (10). On the supply side, good $x$ is now produced by a single firm located in the home country, and good $y$ is produced by a single foreign firm. The production of both goods requires $c$ units of labour per unit of output. We assume that the entire capital stock of each economy is used to set up a production plant in order to produce at all, and we think of profits accruing to each firm as generating an implicit rent $r \times n$ for this fixed factor. This profit income is fully distributed to the consumers in the residence country of the firm. 
Exports of either firm to the other market cause trade costs of $s$ per unit of the good shipped. Hence, per-capita profits of the two firms under DP and OP are

$$
\begin{aligned}
& r_{d}=\left(q_{x}-c-t_{d}\right) x+\left(q_{x}^{*}-c-s-t_{d}^{*}\right) x^{*}, \quad r_{d}^{*}=\left(q_{y}^{*}-c-t_{d}^{*}\right) y^{*}+\left(q_{y}-c-s-t_{d}\right) y \\
& r_{o}=\left(q_{x}-c-t_{o}\right) x+\left(q_{x}^{*}-c-s-t_{o}\right) x^{*}, \quad r_{o}^{*}=\left(q_{y}^{*}-c-t_{o}^{*}\right) y^{*}+\left(q_{y}-c-s-t_{o}^{*}\right) y
\end{aligned}
$$

Eqs. (17a)-(17b) hold for both Cournot and Bertrand competition of firms. In each of the different scenarios analysed in the following we first consider the standard 'reciprocal dumping' model (Brander, 1995, sec. 4), which assumes that markets are segmented and firms maximise profits in each market independently. We then turn briefly to the case where markets are integrated.

With firms behaving as Cournot competitors and assuming that markets are segmented and demand curves are linear as in (10), reaction functions in quantity space are downward-sloping and the quantities supplied by the duopolists are strategic substitutes (Bulow et al., 1985). This result, and the following expressions, are derived in the appendix. Under the DP, which we use to determine the cooperative tax rate, the equilibrium quantities of firms are given by

$$
x=\frac{(2 \beta-\gamma)\left(\alpha-c-t_{d}\right)+\gamma s}{(2 \beta+\gamma)(2 \beta-\gamma)}, \quad y=\frac{(2 \beta-\gamma)\left(\alpha-c-t_{d}\right)-2 \beta s}{(2 \beta+\gamma)(2 \beta-\gamma)} .
$$

The cooperative tax rate in the Cournot duopoly case (superscript $C$ ) is then

$$
t_{c}^{C}=\frac{[(\delta-1)(2 \beta+\gamma)-\beta][2(\alpha-c)-s]}{2[(2 \delta-1)(2 \beta+\gamma)-\beta]} .
$$

From (19) the cooperative tax rate is negative in the Cournot duopoly model when lump-sum taxes exist $(\delta=1)$. The subsidy raises the consumption of both goods $x$ and $y$ and thus corrects the distortion arising from imperfect competition. It is also inferred from (19) that the cooperative commodity tax rate turns positive if $\delta>\bar{\delta}^{C}=$ $(3 \beta+\gamma) /(2 \beta+\gamma)$

\subsection{Destination Principle}

To determine the non-cooperative tax rate under the destination principle, we use (18) together with the inverse demands from (10), profits from (17a), the tax base $b_{d}=x+y$ 
and (8) in (7) to obtain

$$
t_{d}^{C}=\frac{(\delta-1)(2 \beta-\gamma)[2(\alpha-c)-s]-\beta s}{2(2 \delta-1)(2 \beta-\gamma)}
$$

A comparison with (19) shows that the non-cooperative tax rate under the destination principle exceeds the cooperatively chosen tax. An explicit analysis of the tax spillovers provides an intuition for this finding. Using (18) in (10) we see that consumer prices in one country do not depend on the other country's tax rate when markets are segmented and the DP is applied. Hence, as in the benchmark case of perfect competition, there is neither a consumer price spillover nor a public consumption spillover. The remaining spillover on foreign profits is derived by differentiating (17a) and using (18) and (10) in (9). This gives

$$
\frac{d v^{*}}{d t_{d}}=\frac{d r^{*}}{d t_{d}}=\frac{-2 \beta y}{2 \beta+\gamma}<0
$$

Hence, the rent shifting externality and thus the net spillover on foreign welfare is unambiguously negative. A consumption tax in the home country lowers domestic demand for good $y$ and this reduces the profits earned by the foreign firm in the home market. ${ }^{17}$ This provides an incentive to national policymakers to set non-cooperative tax rates in excess of their Pareto optimal levels. This incentive is present in both the homogeneous and the heterogeneous variant of the model $(\beta \geq \gamma)$, and it arises under lump-sum finance and commodity tax finance of public goods.

The analysis of integrated markets assumes that, for reasons of arbitrage, each firm must set the same producer price for its product in the domestic and foreign markets. The analysis of this case, simplified by setting $s=0$, is found in the appendix. The core difference to the segmented market case is that a domestic tax increase, which causes a reduction in the domestic producer price in the firm's optimum, will now also reduce the firm's producer price abroad. With the foreign country's (destinationbased) tax rate unchanged this reduces the foreign consumer price and hence leads to a positive consumer price spillover. The increase in foreign demand in turn raises the foreign tax base. At the same time, the domestic tax increase still causes a negative spillover on foreign profits. When lump-sum taxes exist the public consumption effect is evaluated at a negative cooperative tax rate, and the net effect on foreign welfare

\footnotetext{
${ }^{17}$ This is similar to the incentive for a small country to levy a positive import tariff in imperfectly competitive markets, in order to reduce foreign profit income (Brander and Spencer, 1984).
} 
is unambiguously negative. When commodity tax revenues must be positive, however $\left(\delta>\bar{\delta}^{C}>1\right)$, the public consumption externality turns positive and the net externality will also be positive when $\delta$ is sufficiently large $[\delta>2$; see (A.5) in the appendix].

\subsection{Origin Principle}

Under the origin principle the profit equations in (17b) apply. Again, we initially assume that markets are segmented and determine the production levels for the home firm. These are (see the appendix)

$$
x=\frac{(\alpha-c)}{(2 \beta+\gamma)}+\frac{\gamma\left(s+t_{o}^{*}\right)-2 \beta t_{o}}{\left(4 \beta^{2}-\gamma^{2}\right)}, \quad x^{*}=\frac{(\alpha-c)}{(2 \beta+\gamma)}+\frac{\gamma t_{o}^{*}-2 \beta\left(t_{o}+s\right)}{\left(4 \beta^{2}-\gamma^{2}\right)} .
$$

The foreign firm's production plans $y, y^{*}$ are analogous. To derive the non-cooperative tax rate under the origin principle we use (22) in (10), profits from (17b), the tax base $b_{o}=x+x^{*}$ and $(8)$ in $(7)$ to get

$$
t_{o}^{C}=\frac{(2 \beta-\gamma)\left\{(\delta-1)\left(4 \beta^{2}-\gamma^{2}\right)[2(\alpha-c)-s]-(\alpha-c)\left(2 \beta^{2}+\gamma^{2}+\beta \gamma\right)\right\}+2 \beta \gamma^{2} s}{(2 \beta-\gamma)\left[\gamma(\beta-\gamma)(2 \delta-1)+10 \beta^{2}(\delta-1)+2 \beta \delta(3 \beta+\gamma)\right]} .
$$

In its general form this expression is too complex to compare it to the Pareto efficient tax rate [eq. (19)]. However, in the special case where lump-sum taxes exist $(\delta=1)$ and goods are homogeneous $(\beta=\gamma)$ eq. (23) reduces to $t_{o}^{C}=-[2(\alpha-c)-s] / 4$, which corresponds to the cooperative tax rate in this case. This is the efficiency result for the OP obtained by Keen and Lahiri (1998, Proposition 6). ${ }^{18}$

To develop an understanding for this result, and analyse more general cases, we look at the various spillovers of tax policy. Eq. (22) shows that equilibrium quantities depend on tax rates in both countries. Using this in (10) shows that a domestic tax increase raises foreign consumer prices and thus leads to a negative consumer price spillover. In contrast, the rent spillover is positive as a domestic production tax makes the domestic good more expensive in both national markets and thus increases foreign production $\left(y+y^{*}\right)$. Finally, the foreign tax base increases for the same reason and the sign of

\footnotetext{
${ }^{18}$ Our framework shows that this result extends to the incorporation of trade costs, which are absent in the analysis of Keen and Lahiri. However, this generalization holds only for the case of linear demands (see Haufler, Stähler and Schjelderup, 2002).
} 
the public consumption spillover is the same as the sign of the cooperative tax rate. Using (17b), (22) and (10) and evaluating at the Pareto efficient tax rate gives

$$
\frac{d v^{*}}{d t_{o}}=\frac{\delta(\delta-1) \gamma[2(\alpha-c)-s]}{(2 \beta-\gamma)[(2 \beta+\gamma)(2 \delta-1)-\beta]}-\frac{x^{*}(\beta-\gamma)}{(2 \beta-\gamma)}
$$

The first term in (24) is positive if $\delta>1$, but disappears when lump-sum taxes are available. The second term is negative whenever $\beta>\gamma$ and disappears in the homogeneous duopoly case $(\beta=\gamma)$. When the two special cases $\delta=1$ and $\beta=\gamma$ are combined, the resulting net externality is zero. Hence our treatment shows that the result of Keen and Lahiri (1998, Prop. 6) derives from the interplay of a positive rent spillover and negative consumer price and public consumption spillovers. Note, in particular, that with $\delta=1$ the public consumption spillover is evaluated at a negative Pareto optimal tax rate [see eq. (19)]. Intuitively, the rise in the foreign tax base caused by a domestic tax increase will raise total subsidy payments made by the foreign government, and thus leads to a welfare loss abroad.

Once we depart from this special case, net externalities do arise from non-cooperative taxation under the OP. If lump-sum taxes exist, but goods $x$ and $y$ are differentiated $(\beta>\gamma)$, the net externality is negative and origin-based taxes will be set inefficiently high. Intuitively, a low substitutability between $x$ and $y$ makes it more difficult for the foreign country to shift away from the imported good, strengthening the negative private consumption externality. Conversely, if commodity taxes are positive $(\delta>\bar{\delta}>1)$, but we maintain the assumption that $x$ and $y$ are homogeneous goods, the net externality is positive and tax rates are inefficiently low in the non-cooperative equilibrium. ${ }^{19}$ With integrated markets, and in the absence of trade costs, all welfare effects are unchanged from the above analysis (see the appendix). Intuitively, note from (22) that the optimal outputs produced for the home and the foreign market are identical for $s=0$. Hence a domestic tax increase affects domestic and foreign output in the same way, and it is immaterial whether profits are maximised separately for each market, or with respect to joint output. Our findings in this section are summarised in

\footnotetext{
${ }^{19}$ Keen and Lahiri (1998, Proposition 7) also consider a revenue motive in their analysis and show that for sufficiently low values of their excess burden parameter $(\delta \leq 1.24)$, the origin principle continues to dominate the destination principle (cf. footnote 7 ). Note, however, from (19) that $\delta>1$ is not a sufficient condition for the cooperative tax rate to be positive in this model.
} 
Proposition 2: If goods markets are characterised by international duopoly and the domestic and the foreign firm compete over quantities, the following holds:

(a) under the destination principle, tax rates in the non-cooperative equilibrium (i) are above their Pareto efficient level when markets are segmented (for any level of $\delta$ ), or when markets are integrated and lump-sum taxes exist; (ii) are below their Pareto efficient levels when markets are integrated and $\delta$ is sufficiently high $(\delta>2)$;

(b) under the origin principle, and with either segmented or differentiated markets, tax rates in the non-cooperative equilibrium (i) are at their Pareto efficient level if lump-sum taxes exist $(\delta=1)$ and the taxed goods are homogeneous $(\beta=\gamma)$ [Keen and Lahiri, 1998, Proposition 6]; (ii) are above their Pareto efficient level if $\delta=1$ and the taxed goods are differentiated; (iii) are below their Pareto efficient level when $\delta>\bar{\delta}>1$ is sufficiently high, or when the taxed goods are close substitutes $(\beta \rightarrow \gamma)$.

\section{International duopoly with price competition}

We now turn to the case where the two firms engage in price competition. With linear demand functions, the reaction functions in price space are upward-sloping so that the firms' instruments are strategic complements. The opposite signs of the reaction functions under quantity and price competition are crucial in determining the sign of the optimal export tax in the literature on strategic trade policy (Eaton and Grossman, 1986). Our comparison of the Cournot and Bertrand cases allows us to analyse whether results are equally sensitive in the context of international commodity taxation.

In the analysis of this section we abstract from transport costs, as they significantly complicate the analysis without providing additional insights. Again we first analyse the segmented markets case. The home country's equilibrium prices under the destination principle are given by (see the appendix)

$$
q_{x}=q_{y}=\frac{\alpha(\beta-\gamma)+\beta\left(c+t_{d}\right)}{(2 \beta-\gamma)}
$$

from which the cooperative tax rate for the Bertrand duopoly (superscript $B$ ) can be calculated as

$$
t_{c}^{B}=\frac{(\alpha-c)[(\delta-1)(2 \beta-\gamma)-(\beta-\gamma)]}{(2 \delta-1)(2 \beta-\gamma)-(\beta-\gamma)}
$$


The differences to the cooperative tax rate under quantity competition [eq. (19)] are apparent. In the benchmark case where $\delta=1$ and $\beta=\gamma$, the cooperative tax rate is now zero, since firms will set prices equal to marginal cost in equilibrium. When lumpsum taxes exist and goods are differentiated, then $t_{c}^{B}<0$ follows from (26). Since price competition between firms supplying differentiated goods will not be perfect, a corrective role for government subsidies remains. The condition for the cooperative tax rate to be positive in this setting is $\bar{\delta}^{B}=(3 \beta-2 \gamma) /(2 \beta-\gamma)$.

\subsection{Destination principle}

To derive the non-cooperative tax rate under the DP, we use (25) in the demand functions (11), profits from (17a), the tax base $b_{d}=x+y$ and (8) in (7). This yields

$$
t_{d}^{B}=\frac{(\alpha-c)(\delta-1)}{(2 \delta-1)} .
$$

A comparison with eq. (26) shows that the non-cooperative tax rate will exceed its Pareto efficient level when $\beta>\gamma$, and it will coincide with the cooperative tax when goods are homogeneous. This is clarified by looking at the externalities caused by a domestic tax increase. Observe from (25) that non-cooperative taxation in the destination regime again causes no consumer price spillovers when markets are segmented. Hence, from (11), there will also be no effects on foreign demands and the foreign tax base. The rent spillover on the foreign country is obtained by differentiating foreign profits in (17a). Using this in (9) gives

$$
\frac{d v^{*}}{d t_{d}}=\frac{d r^{*}}{d t_{d}}=\frac{-2 y(\beta-\gamma)}{2 \beta-\gamma} \leq 0
$$

Eq. (28) shows that, for $y>0$, the rent shifting externality is strictly non-positive, and thus has the same sign as under Cournot competition [cf. (21)]. However, the magnitude of the externality is now inversely related to the degree of substitutability between goods $x$ and $y$, which determines the size of foreign rent income. In the special case $\beta=\gamma$ foreign profit income is zero and non-cooperative commodity taxation under the DP yields a Pareto efficient outcome for any level of $\delta$.

The results are modified for integrated markets (see the appendix). If goods are differentiated $(\beta>\gamma)$ and firms earn positive profits, a domestic tax change will lead the 
home firm to adjust quantities so as to reduce the producer price in the home and the foreign market. This leads to a positive consumer price spillover and an increase in the foreign tax base, in addition to the negative rent spillover. As in the case of Cournot competition the public consumption effect and the net effect on foreign welfare will be negative when lump-sum taxes exist, but the net externality turns positive when consumption taxes are positive and $\delta>2$ [see (A.11) in the appendix]. Finally, in the special case of homogeneous goods, foreign producer prices are fixed and tax policies under the DP are not associated with any externalities.

\subsection{Origin principle}

The equilibrium prices under the $\mathrm{OP}$ are derived in the appendix and given by

$$
q_{x}=q_{y}=\frac{\alpha(\beta-\gamma)+\beta c}{(2 \beta-\gamma)}+\frac{\beta\left(2 \beta t_{o}+\gamma t_{o}^{*}\right)}{4 \beta^{2}-\gamma^{2}}
$$

This shows that the externalities of origin-based taxes with Bertrand competition of firms are qualitatively the same as in the Cournot case. A domestic tax increase raises foreign consumer prices and exerts a negative consumer price spillover on the foreign country. At the same time, foreign output $\left(y+y^{*}\right)$, profits, and the foreign tax base all increase. The non-cooperative tax rate is

$$
t_{o}^{B}=\frac{(\beta-\gamma)(\alpha-c)\left[2(\delta-1)\left(4 \beta^{2}-\gamma^{2}\right)-2\left(\beta^{2}-\gamma^{2}\right)-\beta \gamma\right]}{\beta\left(6 \beta^{2}-3 \beta \gamma-\gamma^{2}\right)(2 \delta-1)+4\left(\beta^{3}-\beta \gamma^{2}+\gamma^{3}\right)(\delta-1)} .
$$

From (30) the non-cooperative tax rate is zero if $\beta=\gamma$, which corresponds to the cooperative tax rate (26) when $\delta=1$. Again this is the special case covered in Proposition 6 of Keen and Lahiri (1998), which also applies to Bertrand competition. For more general parameter combinations it is difficult to derive any clear-cut conclusions from (30), and we switch to calculating the externalities on the foreign country. Using (29) along with (11) and (17b) in (9) and evaluating at the cooperative tax rate (26) gives

$$
\frac{d v^{*}}{d t_{o}}=\frac{\beta^{2}(\alpha-c) \delta[2 \gamma(\delta-1)-(\beta-\gamma)]}{(2 \beta+\gamma)(\beta+\gamma)(\beta-\gamma)[2(\delta-1)(2 \beta-\gamma)-(\beta-\gamma)]}
$$

The net spillovers summarised in (31) are very similar to the case of Cournot competition [eq. (24)]. If lump-sum taxes exist $(\delta=1)$, but goods $x$ and $y$ are differentiated, then the public consumption effect and the net externality on foreign welfare are both 
negative, and origin-based taxes will then be set 'too high' in the non-cooperative tax equilibrium. In contrast, if commodity taxes must be positive $\left(\delta>\bar{\delta}^{B}\right)$, the public consumption effect changes its sign and turns positive. If $\delta$ is sufficiently large, or if goods $x$ and $y$ are sufficiently close substitutes, then a domestic tax increase causes a positive net externality on the foreign country. In particular, as $\beta \rightarrow \gamma$ the welfare gain for the foreign country becomes arbitrarily large since, starting from a symmetric equilibrium, the tax base responds infinitely elastic to an increase in home's tax rate. ${ }^{20}$ As with Cournot competition, the firms' maximization problems are identical in the integrated market case when taxes are levied under the origin principle (see the appendix). Hence, the welfare effects derived above are unaffected by this model change. Our results for price competition of firms are summarised in

Proposition 3: If goods markets are characterised by international duopoly and firms compete over prices, the following holds:

(a) under the destination principle, tax rates in the non-cooperative equilibrium (i) are at their Pareto efficient level when goods are homogeneous; (ii) are above their Pareto efficient level when goods are differentiated and markets are segmented, or when markets are integrated and lump-sum taxes exist; (iii) are below their Pareto efficient levels when markets are integrated and $\delta$ is sufficiently high $(\delta>2)$;

(b) under the origin principle, and with either segmented or differentiated markets, tax rates in the non-cooperative equilibrium (i) are at their Pareto efficient level if lump-sum taxes exist and goods $x$ and $y$ are perfect substitutes [Keen and Lahiri, 1998, Proposition 6]; (ii) exceed their Pareto efficient level if $\delta=1$ and goods are differentiated; (iii) are below their Pareto efficient level when $\delta>\bar{\delta}>1$ is sufficiently high, or when the taxed goods are close substitutes $(\beta \rightarrow \gamma)$.

Comparing Propositions 2 and 3 shows that the implications of Cournot and Bertrand competition are rather similar in our analysis. When lump-sum taxes exist $(\delta=1)$, noncooperative commodity taxation under both tax principles will generally lead to tax

\footnotetext{
${ }^{20}$ Note that the homogeneous product case is logically consistent under price competition, so that the equilibrium can be evaluated at $\beta=\gamma$. However, demands are discontinuous in this case (cf. Brander, 1995: 1414). A similar setting with infinitely elastic tax bases arises under Cournot competition when the duopolistic firms are perfectly mobile internationally (Janeba, 1998).
} 
rates that exceed their Pareto efficient level. In comparison with the competitive benchmark (Proposition 1), the incorporation of profits thus introduces a strategic motive for non-cooperative taxation under the DP. In contrast, except for some special cases, the results for the OP are not fundamentally different for competitive and duopolistic market structures. When commodity tax revenues must be used to finance the public good, the net externality is reversed under the OP, if goods are sufficiently close substitutes, and the same is also true in some cases under the DP. Again, these results are obtained for both price and quantity competition of firms. Hence, the distinction between lump-sum finance and commodity tax finance plays a much more important role in our duopoly analysis than the distinction between Cournot and Bertrand competition of firms.

Why are the policy results in our analyis so robust with respect to the nature of competition between firms, whereas the sign of an optimal trade intervention is reversed when firms move from quantity to price competition? The focus of the classical analysis of strategic trade policy is on the case where all output is sold in a third market (Brander and Spencer, 1985; Eaton and Grossman, 1986). Once domestic consumption of the imperfectly competitive goods is incorporated, the motive to subsidise domestic production also appears in the strategic trade policy literature. In fact, in the benchmark case where lump-sum taxes exist $(\delta=1)$ and goods are homogeneous $(\beta=\gamma)$, our results for the origin principle (i.e., a production-based commodity tax) coincide with the results in this literature. Under Cournot competition of firms, the motive to correct the consumption distortion by means of a subsidy reinforces the rent-shifting motive. The non-cooperative production tax is thus unambiguously negative, and it is also Pareto optimal when the firms' production costs are the same (see Bhagwati, Panagariya and Srinivasan, 1998: 407). For the case of Bertrand competition and integrated markets, Eaton and Grossman (1986, Proposition 5) show that the optimal production tax is zero when marginal costs of both firms are constant. ${ }^{21}$ This, however, is precisely the Pareto efficient tax rate in this case [eq. (26)]. Hence these results from the trade literature correspond to both the analysis in Keen and Lahiri (1998, Proposition 6), and to our Propositions $2 \mathrm{~b}(\mathrm{i})$ and $3 \mathrm{~b}(\mathrm{i})$.

\footnotetext{
${ }^{21}$ The consistent conjectures equilibrium stressed in Prop. 5 of Eaton and Grossman (1986) is the Bertrand equilibrium under the assumptions made.
} 


\section{Monopolistic competition and firm mobility}

\subsection{The model}

Strategic interactions between firms, which have been at the root of the oligopoly model analysed in the previous section, are absent in the second branch of new trade theory, monopolistic competition. In the Dixit-Stiglitz-Krugman workhorse model (Dixit and Stiglitz, 1977; Krugman, 1980), good $x$ is to be thought of as a basket of differentiated products, each of which is supplied by a single monopolistic firm producing under increasing returns to scale. For our comparison of the two regimes of commodity taxation we use a version of this model set up by Flam and Helpman (1987) to analyse trade and industrial policies under monopolistic competition. This model has meanwhile become a popular tool for policy analysis (e.g. Martin and Rogers, 1995; Pflüger, 2001). As before, we provide the main elements of the model in the body of the paper and relegate all details to the appendix. ${ }^{22}$

The consumer's upper-tier utility function for the numeraire good $z$ and the basket $x$ is of the logarithmic quasi-linear form $\theta \ln x+z$. Then aggregate demand for the bundle $x$ is given by $x(1, q)=\theta / q$ and the representative consumer's indirect utility is

$$
v\left(1, q_{k}, e, g\right)=-\theta \ln q_{k}+e+\delta g+[\theta(\ln \theta-1)] .
$$

Preferences for the different varieties of good $x$ are described by a CES function, where $\sigma>1$ is the constant elasticity of substitution between any two varieties and $x_{h}$ and $x_{f}$ denote a typical domestic and a typical foreign variety, respectively. These preferences are fully characterised by the following dual consumer price indices for the home country, where the goods index has been dropped from the price terms and $m, m^{*}$ denote the number of domestic and foreign varieties

$$
\begin{gathered}
q_{d}=\left(1+t_{d}\right)\left[m p_{h}^{1-\sigma}+m^{*}\left(\tau p_{f}\right)^{1-\sigma}\right]^{\frac{1}{1-\sigma}}, \\
q_{o}=\left[m\left[\left(1+t_{o}\right) p_{h}\right]^{1-\sigma}+m^{*}\left[\left(1+t_{o}^{*}\right) \tau p_{f}\right]^{1-\sigma}\right]^{\frac{1}{1-\sigma}} .
\end{gathered}
$$

Under each tax regime, the consumer price index depends negatively on the number of domestic and foreign varieties. Two other features, which reflect different modelling

\footnotetext{
${ }^{22}$ For a detailed analysis of commodity taxation in this model, but without a public good, see Haufler and Pflüger (2003).
} 
approaches in the oligopoly and the monopolistic competition literature are also apparent from (32a)-(32b). First, transport costs enter here as a multiplicative factor $\tau>1$ (the 'iceberg' formulation), rather than as the unit trade cost ( $s$ ) employed in the duopoly model. Hence the before-tax price of an imported variety is $\tau p_{f}$, where $p_{f}$ is the price charged by each foreign monopolist, whereas the before-tax price of domestic varieties is $p_{h}$. Second, it is standard in this framework to model (trade) taxes in ad valorem, rather than specific, form. ${ }^{23}$ It proves convenient to follow this practice in our analysis of commodity taxes. The domestic consumer's demands for individual varieties can be recovered by applying Roy's identity to these consumer price indices. In the large group case the perceived elasticity of demand equals $\sigma$, as each producer ignores the influence of his own price on the consumer price index.

Total production of each variety, $X_{h}$, requires one unit of capital as a fixed cost. Production takes place with one unit of labour producing one unit of output so that, with $w=1$ from (4), variable costs equal unity. Market clearing for each domestic variety includes transport costs as an indirect demand. With $x_{h}^{*}$ denoting foreign per capita demand for a domestic variety, the profit of a typical domestic firm is

$$
\pi=\left(p_{h}-1\right) n x_{h}+\left(p_{h}^{*}-1\right) \tau n^{*} x_{h}^{*}-r,
$$

where $\left(n, n^{*}\right)$ is the number of consumers in each country and $r$ is the return to capital. Under the Chamberlinian large group assumption profit-maximisation implies

$$
p_{h}=p_{h}^{*}=\frac{\sigma}{(\sigma-1)}
$$

Using this, the individual demand curves and exploiting symmetry the optimised profits of a representative firm, $\hat{\pi}_{k}, k \in\{d, o\}$, can be calculated and set equal to zero in a long-run Chamberlinian equilibrium

$$
\begin{aligned}
& \hat{\pi}_{d}=\frac{\theta n p_{h}^{1-\sigma}}{\sigma}\left[\left(1+t_{d}\right)^{-\sigma} q_{d}^{\sigma-1}+\left(1+t_{d}^{*}\right)^{-\sigma} \rho\left(q_{d}^{*}\right)^{\sigma-1}\right]-r=0, \\
& \hat{\pi}_{o}=\frac{\theta n p_{h}^{1-\sigma}}{\sigma}\left[\left(1+t_{o}\right)^{-\sigma} q_{o}^{\sigma-1}+\left(1+t_{o}\right)^{-\sigma} \rho\left(q_{o}^{*}\right)^{\sigma-1}\right]-r=0,
\end{aligned}
$$

where $0 \leq \rho \equiv \tau^{1-\sigma}<1$. In the long-run equilibrium the rate of return to capital equals the firms' operating surplus. Since each household owns one unit of capital by

\footnotetext{
${ }^{23}$ Under this assumption the elasticity of demand for each variety is unaffected by the policy instrument (Helpman and Krugman, 1989).
} 
assumption, the return $r$ corresponds directly to the per-capita profit expression in the duopoly model of the previous sections. The new element here is that capital is assumed to be perfectly mobile internationally. International arbitrage implies

$$
r=r^{*}
$$

Under the Flam-Helpman specification, the number of firms in each country, $m$ in home and $m^{*}$ in foreign, is equal to the amount of capital installed. With equal endowments in both countries, the overall number of firms is determined by

$$
m+m^{*}=2 n .
$$

The number of firms in each country and the rate of return to capital in the economy's general equilibrium are jointly determined by (36), the capital market clearing condition (37), price levels [(32a)-(32b)] and zero profit conditions [(35a)-(35b)]. Closedform solutions can be obtained for the three endogenous variables $\left(m_{k}, m_{k}^{*}, r_{k}\right)$ under both commodity tax regimes, which are used to derive all other endogenous variables. These are reported in the appendix [eqs. (A.14)-(A.15)]. The cooperative tax rate in the monopolistic competition model (supercript $M$ ) is then derived as

$$
t_{c}^{M}=(\delta-1)-\frac{1}{\sigma} .
$$

In the presence of a lump-sum tax $(\delta=1)$, the cooperative tax rate is negative and corrects for the mark-up charged by monopolistically competitive producers. When lump-sum taxes are not available, a revenue motive enters the analysis and commodity tax rates will be positive when $\delta>\bar{\delta}^{M}=(\sigma+1) / \sigma$. The same two counteracting motives have also been present in the duopoly model analysed above. Finally, if the different varieties of good $x$ are perfect substitutes $(\sigma \rightarrow \infty)$, the second term in (38) disappears as producers will then charge competitive prices [see (34)]. This corresponds to the case of price competition between duopolistic firms when goods $x$ and $y$ are perfect substitutes and $\beta=\gamma$ [cf. eq. (26)].

\subsection{Destination principle}

The non-cooperative tax rate under the DP is derived in the appendix and given by

$$
t_{d}^{M}=(\delta-1)\left(1-\frac{1}{2 \sigma-1}\right)-\frac{1}{\sigma} .
$$


A comparison with the cooperative tax rate (38) shows that $t_{d}^{M}$ will be Pareto efficient if either a lump-sum tax exists, or if the different varieties of good $x$ are perfect substitutes $(\sigma \rightarrow \infty)$. To understand these conditions, and evaluate more general cases, we analyse the tax spillovers on foreign welfare. These are summarised by (see the appendix)

$$
\frac{d v^{*}}{d t_{d}}=\frac{\theta \sigma^{2}(\delta-1)}{2(\sigma-1)(\sigma \delta-1)^{2}} \geq 0
$$

There are two spillovers under the DP in this model, a negative rent spillover and a positive private consumption spillover. The rent spillover has the same sign and a similar interpretation as in the previous section. It is due to the fact that an increase in the consumption tax reduces domestic demand for the differentiated good, and this lowers the profitability of firms and the worldwide return to capital [see (A.18) in the appendix]. In addition, a private consumption spillover arises in this model because a domestic tax induces part of industry to relocate abroad, and this lowers transport costs and hence the consumer price level in the foreign country [see (A.19)]. Finally, the foreign tax base is not affected by a domestic tax increase under the DP [see (A.22)]. If domestic and foreign varieties are perfect substitutes $(\sigma \rightarrow \infty)$, both of these spillovers will disppear. First, there will be no imports of $x$-goods in this case so that no transport costs must be borne and the foreign consumer price level is unaffected by domestic taxes. Second, producer prices approach marginal costs and the return to capital is zero, eliminating the rent spillover. In this special case the model therefore reduces to the competitive benchmark of section 4 . The other special case arises when lump-sum taxes are available to finance the public good $(\delta=1)$. In this case the positive private consumption spillover and the negative rent spillover are exactly offsetting, and the non-cooperative tax equilibrium under DP is Pareto optimal. This is the result obtained in Haufler and Pflüger (2003, Proposition 2). ${ }^{24}$

Equation (40) reveals that the Pareto efficiency of the DP no longer holds when revenue from commodity taxes must be positive. Introducing a revenue motive causes the optimal destination-based tax rate to increase, affecting the size of both spillovers. In this model the positive private consumption spillover caused by the relocation of firms

\footnotetext{
${ }^{24}$ In the absence of a public good, this result carries over to an upper-tier utility function with a variable own-price elasticity of demand for good $x$, and to a setting where countries have different absolute factor endowments, but the same capital-labour ratio (Haufler and Pflüger, 2003, Sec. 6).
} 
will rise more rapidly than the negative rent spillover. Hence the net spillover on the foreign country turns positive and tax competition under the DP leads to tax rates that are below their Pareto efficient levels. Finally, comparing (39) with (38) shows that, for any given level of $\delta$, the deviation from the cooperative tax rate is the smaller, the larger is the elasticity of substitution $\sigma$.

\subsection{Origin principle}

Under the origin principle, the non-cooperative tax rate is (see the appendix)

$$
t_{o}^{M}=\frac{(1-\rho)\left[2(\delta-1) \sigma^{2}-(2 \sigma \delta-1)(1-\rho)-2 \delta \sigma^{2} \rho\right]}{\sigma\{[2 \sigma-(1-\rho)](1-\rho)+4 \delta \sigma(\sigma-1) \rho\}},
$$

where $0 \leq \rho \equiv \tau^{1-\sigma}<1$ should be recalled. If lump-sum taxes exist $(\delta=1)$, the non-cooperative tax rate under $\mathrm{OP}$ is seen to be unambiguously negative, and it does not correspond to the cooperative tax rate (38) in this case.

We consider again the three familiar spillovers that a domestic tax change has on the foreign economy. The consumer price spillover consists of two components in this model. First, commodity taxes can be partly exported to foreign consumers when taxation follows the OP, and this effect is clearly negative. There is also a positive second effect on foreign consumers, however, as a domestic tax increase leads firms to relocate to the foreign country and reduces foreign transport costs. It can be shown that the second effect dominates and the net effect is to lower foreign consumer prices [see (A.17) and (A.20) in the appendix]. Hence, contrary to the duopoly model, the consumer price spillover under the $\mathrm{OP}$ is now positive. The sign of the rent spillover is also reversed from the duopoly model, and is now negative. The reason is that the reduced profitability of the home market is transmitted abroad through international firm mobility, and the negative effect on the return to capital is the same as under destination-based taxes [see (A.18)]. Finally, there is a public consumption externality under the OP, which has the same sign as the cooperatively chosen tax [see (A.23)]. The tax spillovers on the foreign economy are summarised by

$$
\begin{gathered}
\frac{d v^{*}}{d t_{o}}=\frac{(\delta-1) \theta \sigma^{2}\left\{4 \rho(\sigma-1)(1+\rho)(\delta \sigma-1)+(1-\rho)^{2}\left[2 \sigma \rho(1+2 \rho)+1+\rho-\rho^{2}+\rho^{3}\right]\right\}}{2(\sigma-1)(\sigma \delta-1)^{2}(1+\rho)(1-\rho)^{2}} \\
+\frac{\sigma \theta\left\{(1+\rho)\left[(1-\rho)^{2}+4 \sigma \rho\right]\left[(1-\rho)^{2}-1\right]-2 \rho(\sigma-1)(1-\rho)^{2}\right\}}{2(\sigma \delta-1)^{2}(1+\rho)(1-\rho)^{2}}
\end{gathered}
$$


Consider first the case where lump-sum taxes exist $(\delta=1)$ and only the last line in (42) remains. Recalling that $0 \leq \rho<1$ it is then seen that the net spillover on foreign welfare is negative. The main reason is that the foreign country levies a negative tax rate in this case, so that an increase in the foreign tax base implies a negative public consumption spillover on the foreign economy.

When commodity taxes must be used to finance the public good $\left(\delta>\bar{\delta}^{M}\right)$ the cooperatively chosen tax rate and hence the public consumption spillover turn positive. Substituting $\bar{\delta}^{M}=(\sigma+1) / \sigma$ from (38) into (42) it can be shown that the overall effect $d v^{*} / d t_{o}$ then switches its sign and also turns positive. Hence, when commodity tax rates must be positive, non-cooperative taxation under the OP leads to tax levels below their Pareto efficient values. Our results for the monopolistic competition model are summarised in

Proposition 4: If goods markets are characterised by monopolistic competition, and firms are mobile internationally, the following holds:

(a) under the destination principle, tax rates in the non-cooperative equilibrium (i) are at their Pareto efficient level when $\sigma \rightarrow \infty$, or when lump-sum taxes exist [Haufler and Pflüger, 2003, Proposition 2]; (ii) are below their Pareto efficient levels when domestic and foreign varieties are differentiated and $\delta>\bar{\delta}>1$;

(b) under the origin principle, tax rates in the non-cooperative equilibrium (i) are above their Pareto efficient level if lump-sum taxes exist; (ii) are below their efficient level when $\delta>\bar{\delta}>1$.

These results can be compared to the analysis of imperfectly competitive markets in Lockwood (2001, sec. 4 and 6). His model shares with our analysis the assumption that goods are differentiated, but it does not allow for transport costs and international mobility of firms. This implies that the private consumption spillover working through the relocation of firms is absent, and the case where the rent spillover is exactly offset by a private consumption spillover when lump-sum taxes exist cannot arise in Lockwood's analysis. Therefore, the non-cooperative tax equilibrium under the DP is Pareto efficient only if the rent spillover is also zero (see Lockwood, 2001, Prop. 8). This corresponds to the case $\sigma \rightarrow \infty$ in Proposition 4a(i). 


\section{Comparison of results}

To compare our results across the different models, Table 1 summarises the signs of the three principal externalities, and the net effects, for both the destination and origin regimes.

******** Table 1 about here $* * * * * * * *$

Several conclusions emerge from this synopsis. First, in models of imperfect competition, Pareto efficient choices can not generally be expected from non-cooperative tax setting under either tax regime. Special cases that have been discussed in the previous literature show that non-cooperative taxation under either the OP (in the duopoly model; see Keen and Lahiri, 1998) or the DP (in the monopolistic competition model; see Haufler and Pflüger, 2003) can lead to a Pareto efficient outcome. However, all these results are specific to a particular model of imperfect competition. Perhaps even more importantly, they all refer to situations in which lump-sum taxes exist. In the more realistic case where commodity taxes must be used to finance a public good $(\delta>\bar{\delta}>1)$, Table 1 shows, in particular, that a Pareto efficient outcome cannot be obtained under the origin principle in any of the models analysed.

Second, incorporating a government revenue motive is critical to determine the net spillovers of tax policy. If a spillover on the foreign tax base exists, it has the same sign as the cooperative tax rate. The latter will generally be negative when lump-sum taxes exist (as commodity taxes are then used to correct the product market distortion), but turns positive when consumption tax revenue must be positive to provide the public good. Table 1 shows that this is particularly relevant under the OP, where a change in the sign of the public consumption spillover switches the sign of the net externality if either the consumer's valuation of the public good is sufficiently large, or the taxed goods are close substitutes. If one of these conditions is fulfilled, then non-cooperative taxation under the OP leads to inefficiently low tax rates in all models of imperfect competition analysed, just as in the benchmark case of perfect competition.

Third, under the DP the consumer price and rent spillovers generally follow a similar pattern in the different models of imperfect competition. A domestic consumption tax increase, which reduces the profitability of the domestic market, has a negative effect 
on foreign rent income, whereas the consumer price spillover is non-negative. Under the OP, however, introducing firm mobility and trade costs in the monopolistic competition model reverses the (net) sign of both of these spillovers in comparison to the duopoly case.

Fourth, the degree of substitutability between the taxed goods plays a critical role in both the Bertrand duopoly model and in the model of monopolistic competition. In these models the size of the net spillover under the DP falls when the goods produced in imperfectly competitive markets become more homogeneous, and the equilibrium profits earned by non-competitive firms are accordingly reduced. In the limiting case where domestic and foreign goods are perfect substitutes, the implications of these two models approach those of the competitive benchmark, and the dominance of the destination principle in perfectly competitive markets carries over to these scenarios.

\section{Conclusions}

The purpose of this paper has been to compare non-cooperative commodity taxation under the destination and origin principles under a variety of assumptions about market structure. It is in the nature of such an analysis that completely clear-cut results for the preferred international commodity tax regime cannot be expected. In fact, our analysis has shown that no international tax regime can be expected to generally dominate the other under conditions of imperfect competition. Nevertheless, some common patterns have emerged. Perhaps most importantly, we have seen that when commodity taxes must be used to finance a public good, non-cooperative taxation under the origin principle is likely to lead to inefficiently low tax rates, irrespective of the precise model of imperfect competition employed. Therefore, the policy concern that a move to the origin principle could lead to a harmful downward competition of commodity tax rates is not diminished when imperfect competition in product markets is taken into account. Under the destination principle, tax base externalities are generally less important, even under imperfect competition. Instead, a rent shifting motive is the most prevalent externality under this tax regime, which will generally raise tax rates above their efficient levels. The size of this externality depends on the level of profits that foreign firms can earn in the domestic market. It is often argued that the 'pro-competitive effect' of 
international market integration (Baldwin and Venables, 1995) causes the rents from product heterogeneity to fall over time, a development that can be captured by increasing the substitutability between domestic and foreign goods. In this case several of the models analysed in this paper predict that destination-based taxes will approach their Pareto efficient levels. Increasing market integration will thus strengthen the economic efficiency argument for the destination regime, even though it may simultaneously strengthen the administrative argument for a switch to the origin principle.

One should be careful, though, not to draw too firm conclusions from our analysis. First of all, the different models still exhibit a large variety of results. Moreover, the analysis has relied heavily on the assumption that countries are symmetric in all respects. While this assumption clearly implies some loss of generality, it has allowed us to focus on a limited number of parameters that critically determine model results. In particular, the major role that the introduction of a government revenue objective has played in this paper should also be of interest for international trade analyses which, with few exceptions, postulate that lump-sum taxes exist. 
Table 1: Summary of spillover effects under destination and origin regimes

\begin{tabular}{|c|c|c|c|c|c|c|c|c|}
\hline & \multicolumn{4}{|c|}{ Destination Principle } & \multicolumn{4}{|c|}{ Origin Principle } \\
\hline & $\begin{array}{l}\text { priv. } \\
\text { cons. }\end{array}$ & $\begin{array}{l}\text { rent } \\
\text { spill. }\end{array}$ & $\begin{array}{l}\text { publ. } \\
\text { cons. }\end{array}$ & $\begin{array}{l}\text { net } \\
\text { spill. }\end{array}$ & $\begin{array}{l}\text { priv. } \\
\text { cons. }\end{array}$ & $\begin{array}{l}\text { rent } \\
\text { spill. }\end{array}$ & $\begin{array}{l}\text { publ. } \\
\text { cons. }\end{array}$ & $\begin{array}{l}\text { net } \\
\text { spill. }\end{array}$ \\
\hline \multicolumn{9}{|c|}{ (1) Perfect competition } \\
\hline$\delta=1$ & 0 & 0 & 0 & 0 & $(-)$ & 0 & 0 & $(-)$ \\
\hline$\delta>\bar{\delta}^{P}=1$ & 0 & 0 & 0 & 0 & $(-)$ & 0 & $(+)$ & $(+,-)^{a}$ \\
\hline \multicolumn{9}{|c|}{ (2a) Cournot duopoly: segmented markets } \\
\hline$\delta=1$ & 0 & $(-)$ & 0 & $(-)$ & $(-)$ & $(+)$ & $(-)$ & $(-, 0)^{b}$ \\
\hline$\delta>\bar{\delta}^{C}>1$ & 0 & $(-)$ & 0 & $(-)$ & $(-)$ & $(+)$ & $(+)$ & $(+,-)^{a}$ \\
\hline \multicolumn{9}{|c|}{ (2b) Cournot duopoly: integrated markets } \\
\hline$\delta=1$ & $(+)$ & $(-)$ & $(-)$ & $(-)$ & $(-)$ & $(+)$ & $(-)$ & $(-, 0)^{b}$ \\
\hline$\delta>\bar{\delta}^{C}>1$ & $(+)$ & $(-)$ & $(+)$ & $(+,-)^{c}$ & $(-)$ & $(+)$ & $(+)$ & $(+,-)^{a}$ \\
\hline \multicolumn{9}{|c|}{ (3a) Bertrand duopoly: segmented markets } \\
\hline$\delta=1$ & 0 & $(-, 0)^{b}$ & 0 & $(-, 0)^{b}$ & $(-)$ & $(+)$ & $(-)$ & $(-, 0)^{b}$ \\
\hline$\delta>\bar{\delta}^{B} \geq 1$ & 0 & $(-, 0)^{b}$ & 0 & $(-, 0)^{b}$ & $(-)$ & $(+)$ & $(+)$ & $(+,-)^{a}$ \\
\hline \multicolumn{9}{|c|}{ (3b) Bertrand duopoly: integrated markets } \\
\hline$\delta=1$ & $(+, 0)^{b}$ & $(-, 0)^{b}$ & $(-, 0)^{b}$ & $(-, 0)^{b}$ & $(-)$ & $(+)$ & $(-)$ & $(-, 0)^{b}$ \\
\hline$\delta>\bar{\delta}^{B} \geq 1$ & $(+, 0)^{b}$ & $(-, 0)^{b}$ & $(+, 0)^{b}$ & $(+,-, 0)^{b, c}$ & $(-)$ & $(+)$ & $(+)$ & $(+,-)^{a}$ \\
\hline \multicolumn{9}{|c|}{ (4) Monopolistic competition } \\
\hline$\delta=1$ & $(+, 0)^{b}$ & $(-, 0)^{b}$ & 0 & 0 & $(+)$ & $(-)$ & $(-)$ & $(-)$ \\
\hline$\delta>\bar{\delta}^{M} \geq 1$ & $(+, 0)^{b}$ & $(-, 0)^{b}$ & 0 & $(+, 0)^{b}$ & $(+)$ & $(-)$ & $(+)$ & $(+)$ \\
\hline
\end{tabular}

$(+)$ : positive spillover, $\quad(-)$ : negative spillover, $\quad$ 0: no spillover

${ }^{a}$ positive effect if $\delta$ is sufficiently large, or if taxed goods are close substitutes

${ }^{b}$ zero effect only if goods are perfect substitutes

${ }^{c}$ positive effect if $\delta$ is sufficiently large $(\delta>2)$ 


\section{Appendix to Section 5}

As a first step in the derivation of the cooperative tax rate we differentiate (17a) and its foreign counterpart and substitute into (8) and (9). This gives

$$
\begin{array}{r}
\frac{d v+d v^{*}}{d t_{d}}=(\delta-1)(x+y)+\left(q_{x}-c-t_{d}\right) \frac{d x}{d t_{d}}+\left(q_{y}-c-s-t_{d}\right) \frac{d y}{d t_{d}} \\
+\left(q_{x}^{*}-c-s-t_{d}^{*}\right) \frac{d x^{*}}{d t_{d}}+\left(q_{y}^{*}-c-t_{d}^{*}\right) \frac{d y^{*}}{d t_{d}}+\delta t_{d}\left[\frac{d x}{d t_{d}}+\frac{d x^{*}}{d t_{d}}+\frac{d y}{d t_{d}}+\frac{d y^{*}}{d t_{d}}\right] .
\end{array}
$$

This equation holds for quantity and price competition of firms, and for segmented and integrated markets.

\section{Destination Principle}

When markets are segmented, the first-order conditions determining home's consumption are

$$
\frac{\partial r_{d}}{\partial x}=q_{x}-c-t-\beta x=0, \quad \frac{\partial r_{d}^{*}}{\partial y}=q_{y}-c-s-t-\beta y=0,
$$

where $\partial q_{x} / \partial x=\partial q_{y} / \partial y=-\beta$ has been used from (10). These first-order conditions imply negatively sloped reaction functions:

$$
\frac{\partial^{2} r}{\partial x \partial y}=\frac{\partial q_{x}}{\partial y}=-\gamma=\frac{\partial^{2} r^{*}}{\partial x \partial y}<0 .
$$

Substituting (A.2) in (10) and solving the set of simultaneous equations yields the reduced forms for $x$ and $y$ given in (18).

To determine the cooperative tax rate, note from (18) that $d x^{*} / d t_{d}=d y^{*} / d t_{d}=0$. Using (18) to calculate the remaining derivatives and the first-order conditions (A.2), gives the cooperative tax rate in the main text [eq. (19)].

When markets are integrated, and $s=0$, the problem for the home firm and the resulting first-order condition are

$$
\max _{x+x^{*}}\left(p_{x}-c\right)\left(x+x^{*}\right) \rightarrow\left(p_{x}-c\right)-\frac{\beta}{2}\left(x+x^{*}\right)=0,
$$

where $p_{x}$ is the common producer price in the two countries and $\partial p_{x} / \partial x=\partial q_{x} / \partial x=$ $-\beta$ from (10). Substituting (10), proceeding likewise for the foreign firm and making use of symmetry when $s=0$ gives

$$
x=y=\frac{(\alpha-c)}{2 \beta+\gamma}+\frac{\beta t_{d}^{*}-(3 \beta+2 \gamma) t_{d}}{2(\beta+\gamma)(2 \beta+\gamma)}, \quad x^{*}=y^{*}=\frac{(\alpha-c)}{2 \beta+\gamma}+\frac{\beta t_{d}-(3 \beta+2 \gamma) t_{d}^{*}}{2(\beta+\gamma)(2 \beta+\gamma)} .
$$


Using (A.4) and (10) in (A.1) shows that the cooperative tax rate in the integrated market equilibrium is the same as with segmented markets [eq. (19); where $s=0$ ]. To evaluate the tax spillovers on foreign welfare, we use (A.4) and (10) along with (17a) in (9) and evaluate the effects at the Pareto optimal tax rate (19). This gives

$$
\frac{d v^{*}}{d t_{d}}=\frac{(\alpha-c) \beta \delta(\delta-2)}{(\beta+\gamma)[(2 \delta-1)(2 \beta+\gamma)-\beta]}
$$

\section{Origin Principle}

With segmented markets, the two firms' first-order conditions are, using (10)

$$
\begin{array}{r}
q_{x}-c-t-\beta x=0, \quad q_{y}-c-s-t^{*}-\beta y=0, \\
q_{x}^{*}-c-t-\beta x^{*}=0, \quad q_{y}^{*}-c-t^{*}-\beta y^{*}=0 .
\end{array}
$$

Using (A.6) in (10) determines the consumption levels in each country given in (22).

With integrated markets, and setting $s=0$, equation set (A.6) reduces to the two first-order conditions

$$
2\left(q_{x}-c-t\right)-\beta\left(x+x^{*}\right)=0, \quad 2\left(q_{y}-c-t^{*}\right)-\beta\left(y+y^{*}\right)=0 .
$$

Solving the set of simultaneous equations and using (10) yields the same equilibrium quantities as with segmented markets [eq. (22)].

\section{Appendix to Section 6}

\section{Destination Principle}

When markets are segmented, and $s=0$, the first-order conditions for profit maximization are

$$
\frac{\partial r_{d}}{\partial q_{x}}=x-\frac{\left(q_{x}-c-t\right) \beta}{\left(\beta^{2}-\gamma^{2}\right)}=0, \quad \frac{\partial r_{d}^{*}}{\partial q_{y}}=y-\frac{\left(q_{y}-c-t\right) \beta}{\left(\beta^{2}-\gamma^{2}\right)}=0,
$$

where $\partial x / \partial q_{x}=\partial y / \partial q_{y}=-\beta /\left(\beta^{2}-\gamma^{2}\right)$ from (11). These first-order conditions imply positively sloped reaction functions. Using (11) gives

$$
\frac{\partial^{2} r}{\partial q_{x} \partial q_{y}}=\frac{\partial x}{\partial q_{y}}=\frac{\gamma}{\left(\beta^{2}-\gamma^{2}\right)}=\frac{\partial^{2} r^{*}}{\partial q_{x} \partial q_{y}}>0
$$

which has the opposite sign as (A.3). 
Equation (A.1) remains the starting point for the determination of the Pareto efficient tax rate. Substituting (A.8) in (11) and solving the set of simultaneous equations yields the reduced forms for $q_{x}$ and $q_{y}$ given in (25). Using (25) and the first-order conditions (A.8) along with (11) in (A.1) gives the cooperative tax rate [eq. (26)].

When markets are integrated, the problem for the home firm, and the resulting firstorder condition is

$$
\max _{p_{x}}\left(p_{x}-c\right)\left(x+x^{*}\right) \quad \rightarrow \quad\left(x+x^{*}\right)-\left(p_{x}-c\right) \frac{2 \beta}{\beta^{2}-\gamma^{2}}=0
$$

where $p_{x}$ is the producer price and $\partial x / \partial q_{x}=\partial y / \partial q_{y}=-\beta /\left(\beta^{2}-\gamma^{2}\right)$ from (11). Proceeding analogously for the foreign firm and solving gives Bertrand equilibrium prices

$$
q_{x}=q_{y}=\frac{2[\alpha(\beta-\gamma)+c \beta]+t_{d}(3 \beta-\gamma)-t_{d}^{*}(\beta-\gamma)}{2(2 \beta-\gamma)} .
$$

Using (A.10), the analogous expressions for $q_{x}^{*}$ and $q_{y}^{*}$ and (11) in (A.1) and setting $s=0$ shows that the cooperative tax rate in the integrated market equilibrium is the same as with segmented markets [eq. (26)]. To evaluate the spillovers on foreign welfare, we use (A.10) along with (11) and (17a) in (9) and use (26). This gives

$$
\frac{d v^{*}}{d t_{d}}=\frac{(\alpha-c)(\beta-\gamma) \delta(\delta-2)}{(\beta+\gamma)[(2 \delta-1)(2 \beta-\gamma)-(\beta-\gamma)]}
$$

\section{Origin Principle}

With segmented markets, the first-order conditions for the home firm are, from (17b)

$$
\frac{\partial r_{o}}{\partial q_{x}}=x-\frac{\left(q_{x}-c-t_{o}\right) \beta}{\left(\beta^{2}-\gamma^{2}\right)}=0, \quad \frac{\partial r_{o}}{\partial q_{x}^{*}}=x^{*}-\frac{\left(q_{x}^{*}-c-t_{o}\right) \beta}{\left(\beta^{2}-\gamma^{2}\right)}=0,
$$

and analogously for the foreign firm, where $\partial x / \partial q_{x}=\partial y / \partial q_{y}=-\beta /\left(\beta^{2}-\gamma^{2}\right)$ from (11). Substituting in (11) and solving the resulting set of simultaneous equations determines Bertrand equilibrium prices in (29). To derive the non-cooperative tax rate we use (29) in (11), profits from (17b), the tax base $b_{o}=x+x^{*}$ and (8) in (7). This gives eq. (30) in the main text.

With integrated markets equation set (A.12) changes to

$$
\frac{\partial r_{o}}{\partial q_{x}}=\left(x+x^{*}\right)-\frac{2\left(q_{x}-c-t_{o}\right) \beta}{\left(\beta^{2}-\gamma^{2}\right)}=0, \frac{\partial r_{o}^{*}}{\partial q_{y}}=\left(y+y^{*}\right)-\frac{2\left(q_{y}-c-t_{o}^{*}\right) \beta}{\left(\beta^{2}-\gamma^{2}\right)}=0 .
$$

Using this in (11) yields the same equilibrium prices as with segmented markets [eq. (29)]. 


\section{Appendix to Section 7}

The equilibrium values for $m_{d}, m_{d}^{*}$ and $r_{d}$ under the destination principle are

$$
\begin{gathered}
m_{d}=\frac{2 n\left[\left(1+t_{d}^{*}\right)-\rho\left(1+t_{d}\right)\right]}{(1-\rho)\left[\left(1+t_{d}\right)+\left(1+t_{d}^{*}\right)\right]}, \quad m_{d}^{*}=\frac{2 n\left[\left(1+t_{d}\right)-\rho\left(1+t_{d}^{*}\right)\right]}{(1-\rho)\left[\left(1+t_{d}\right)+\left(1+t_{d}^{*}\right)\right]}, \\
r_{d}=\frac{\theta\left[\left(1+t_{d}\right)+\left(1+t_{d}^{*}\right)\right]}{2 \sigma\left(1+t_{d}\right)\left(1+t_{d}^{*}\right)} .
\end{gathered}
$$

Under the origin principle, the equilibrium values for $m_{o}, m_{o}^{*}$ and $r_{o}$ are

$$
\begin{aligned}
& m_{o}=\frac{2 n\left(1+t_{o}^{*}\right)\left(1+t_{o}\right)^{\sigma}\left[\left(1+\rho^{2}\right)\left(1+t_{o}^{*}\right)^{\sigma}-2 \rho\left(1+t_{o}\right)^{\sigma}\right]}{\varepsilon\left(1+\rho^{2}\right)\left[\left(1+t_{o}\right)+\left(1+t_{o}^{*}\right)\right]-2 \rho\left[\left(1+t_{o}\right)\left(1+t_{o}^{*}\right)^{2 \sigma}+\left(1+t_{o}^{*}\right)\left(1+t_{o}\right)^{2 \sigma}\right]}, \\
& m_{o}^{*}=\frac{2 n\left(1+t_{o}\right)\left(1+t_{o}^{*}\right)^{\sigma}\left[\left(1+\rho^{2}\right)\left(1+t_{o}\right)^{\sigma}-2 \rho\left(1+t_{o}^{*}\right)^{\sigma}\right]}{\varepsilon\left(1+\rho^{2}\right)\left[\left(1+t_{o}\right)+\left(1+t_{o}^{*}\right)\right]-2 \rho\left[\left(1+t_{o}\right)\left(1+t_{o}^{*}\right)^{2 \sigma}+\left(1+t_{o}^{*}\right)\left(1+t_{o}\right)^{2 \sigma}\right]}, \\
& r_{o}=\frac{\theta\left\{\varepsilon\left(1+\rho^{2}\right)\left[\left(1+t_{o}\right)^{-1}+\left(1+t_{o}^{*}\right)^{-1}\right]-2 \rho\left[\left(1+t_{o}\right)^{2 \sigma-1}+\left(1+t_{o}^{*}\right)^{2 \sigma-1}\right]\right\}}{2 \sigma\left[\left(1+t_{o}\right)^{\sigma}-\rho\left(1+t_{o}^{*}\right)^{\sigma}\right]\left[\left(1+t_{o}^{*}\right)^{\sigma}-\rho\left(1+t_{o}\right)^{\sigma}\right]},
\end{aligned}
$$

where $\varepsilon \equiv\left(1+t_{o}\right)^{\sigma}\left(1+t_{o}^{*}\right)^{\sigma}$.

Differentiating the equation sets (A.14) and (A.15) and evaluating around a symmetric equilibrium yields

$$
\begin{gathered}
\frac{d m_{d}}{d t_{d}}=\frac{-n(1+\rho)}{2\left(1+t_{d}\right)(1-\rho)}=-\frac{d m_{d}^{*}}{d t_{d}} \\
\frac{d m_{o}}{d t_{o}}=\frac{-n\left[1+2 \rho(2 \sigma-1)+\rho^{2}\right]}{2\left(1+t_{o}\right)(1-\rho)^{2}}=-\frac{d m_{o}^{*}}{d t_{o}}<0, \\
\frac{d r_{d}}{d t_{d}}=\frac{d r_{d}^{*}}{d t_{d}}=\frac{-\theta}{2 \sigma\left(1+t_{d}\right)^{2}}<0, \quad \frac{d r_{o}}{d t_{o}}=\frac{d r_{o}^{*}}{d t_{o}}=\frac{-\theta}{2 \sigma\left(1+t_{o}\right)^{2}}<0 .
\end{gathered}
$$

The tax-induced changes in the domestic and the foreign price level are derived from (32a)-(32b) and their foreign counterparts

$$
\begin{array}{ccc}
\frac{d q_{d}}{d t_{d}}=\frac{q_{d}}{\left(1+t_{d}\right)}-\frac{q_{d}}{(\sigma-1) m} \frac{(1-\rho)}{(1+\rho)} \frac{d m_{d}}{d t_{d}}, & \frac{d q_{d}^{*}}{d t_{d}}=\frac{q_{d}^{*}}{(\sigma-1) m} \frac{(1-\rho)}{(1+\rho)} \frac{d m_{d}}{d t_{d}} . \quad \text { (A.19) } \\
\frac{d q_{o}}{d t_{o}}=\frac{q_{o}}{(1+\rho)}\left[\frac{1}{\left(1+t_{o}\right)}-\frac{(1-\rho)}{(\sigma-1) m} \frac{d m_{o}}{d t_{o}}\right], & \frac{d q_{o}^{*}}{d t_{o}}=\frac{q_{o}^{*}}{(1+\rho)}\left[\frac{\rho}{\left(1+t_{o}\right)}+\frac{(1-\rho)}{(\sigma-1) m} \frac{d m_{o}}{d t_{o}}\right] .
\end{array}
$$

The tax base under DP equals per-capita expenditures for $x$-goods, valued at producer prices. Under OP the tax base equals the per-capita value of domestic production

$$
b_{d}=m p_{h} x_{h}+m^{*} \tau p_{f} x_{f}=\frac{q_{d} x}{\left(1+t_{d}\right)}=\frac{\theta}{\left(1+t_{d}\right)}
$$




$$
b_{o}=m\left[p_{h} x_{h}+\tau p_{h}^{*} x_{h}^{*}\right]=p_{h} m \frac{X_{h}}{n}=\frac{\sigma m r}{n} .
$$

Under DP the last step uses the property that the consumer allocates $q x=\theta$ of her budget to differentiated products. Under OP, the last step follows from (33), (34) and market clearing. The effects of a tax change on public good provision are

$$
\begin{gathered}
\frac{d g_{d}}{d t_{d}}=b_{d}+t_{d} \frac{d b_{d}}{d t_{d}}=\frac{\theta}{\left(1+t_{d}\right)^{2}}, \quad \frac{d g_{d}^{*}}{d t_{d}}=t_{d}^{*} \frac{d b_{d}^{*}}{d t_{d}}=0 \\
\frac{d g_{o}}{d t_{o}}=\frac{\sigma m r}{n}-t_{o} \frac{\theta}{\left(1+t_{o}\right)^{2}}\left[1+\frac{2 \sigma \rho}{(1-\rho)^{2}}\right], \quad \frac{d g_{o}^{*}}{\partial t_{o}}=t_{o}^{*} \frac{\theta}{\left(1+t_{o}\right)^{2}} \frac{2 \sigma \rho}{(1-\rho)^{2}} .
\end{gathered}
$$

To derive the cooperative tax rate, (A.18), (A.19) and (A.22) are substituted into (8) and (9). Using this in (6) and solving for the cooperative tax rate gives eq. (38).

The non-cooperative tax rate under DP is obtained by substituting (A.18), (A.19) and (A.22) into (8) and solving for $t_{d}$. This gives eq. (39). To determine the spillovers on the foreign country, the corresponding expressions in (A.18), (A.19) and (A.22) are substituted into (9). Evaluating at the cooperative tax rate (38) gives eq. (40).

To derive the non-cooperative tax rate under OP, eqs. (A.18), (A.20) and (A.23) are substituted into (8). Solving for $t_{o}$ gives eq. (41). Substituting the effects on the foreign variables into (9) and evaluating at the cooperative tax rate gives eq. (42). 


\section{References}

Baldwin, R. and A.J. Venables (1995), Regional economic integration, in: G. Grossman and K. Rogoff (eds.), Handbook of International Economics, Vol.III, 1597-1644. Elsevier Science, Amsterdam.

Bhagwati, J., A. Panagariya and T.N. Srinivasan (1998), Lectures on international trade, 2nd ed. MIT Press, Cambridge/Mass.

Brander, J.A. (1995), Strategic trade policy, in: G. Grossman and K. Rogoff (eds.), Handbook of international economics, vol. III. Elsevier Science, Amsterdam, 13951455.

Brander, J.A. and B. Spencer (1984), Tariff protection and imperfect competition, in: H. Kierzkowski (ed.), Monopolistic competition and international trade. Oxford University Press, 194-206.

Brander, J.A. and B. Spencer (1985), Export subsidies and international market share rivalry. Journal of International Economics 18, 83-100.

Bucovetsky, S. (1991), Asymmetric tax competition. Journal of Urban Economics 30, 167-181.

Bulow, J., J. Geanakoplos and P. Klemperer (1985), Multimarket oligopoly: Strategic substitutes and complements. Journal of Political Economy 93, 488-511.

Cheng, L.K. (1988), Assisting domestic industries under international oligopoly: The relevance of the nature of competition to optimal policies. American Economic Review 78, 746-758.

Cnossen, S. (1998), Global trends and issues in value added taxation. International Tax and Public Finance 5, 399-428.

Dixit, A. and J.E. Stiglitz (1977), Monopolistic competition and optimum product diversity. American Economic Review 67, 297-308.

Eaton, J. and G.M. Grossman (1986), Optimal trade policy under oligopoly. Quarterly Journal of Economics 101, 383-406. 
Flam, H. and E. Helpman (1987), Industrial policy under monopolistic competition. Journal of International Economics 22, 79-102.

Goolsbee, A., 2000, In a world without borders: The impact of taxes on Internet commerce. Quarterly Journal of Economics 115, 561-576.

Haufler, A. and M. Pflüger (2003), International commodity taxation under monopolistic competition. Journal of Public Economic Theory, forthcoming.

Haufler, A. and G. Schjelderup (2003), Tacit collusion and international commodity taxation. Journal of Public Economics, forthcoming.

Haufler, A., G. Schjelderup and F. Stähler (2002), Economic integration and the choice of commodity tax base under imperfect competition. Mimeo, University of Munich.

Helpman, E. and P. Krugman (1989), Trade policy and market structure. MIT Press, Cambridge (Mass.).

Janeba, E. (1998), Tax competition in imperfectly competitive markets. Journal of International Economics 44, 134-153.

Kanbur, R. and M. Keen (1993), Jeux sans frontières: Tax competition and tax coordination when countries differ in size. American Economic Review 83, 877-892.

Keen, M. and S. Lahiri (1998), The comparison between destination and origin principles under imperfect competition. Journal of International Economics 45, 323350.

Keen, M. and S. Smith (1996), The future of value-added tax in the European Union. Economic Policy 23, 375-420.

Krugman, P. (1980), Scale economies, product differentiation, and the pattern of trade. American Economic Review 70, 950-959.

Lockwood, B. (1993), Commodity tax competition under destination and origin principles. Journal of Public Economics 53, 141-162. 
Lockwood, B. (2001), Tax competition and tax co-ordination under destination and origin principles: a synthesis. Journal of Public Economics 81, 279-319.

Lockwood, B., D. de Meza and G. Myles (1994), When are origin and destination regimes equivalent? International Tax and Public Finance 1, 5-24.

Markusen, J.R. and A.J. Venables (1988), Trade policy with increasing returns and imperfect competition. Journal of International Economics 24, 299-316.

Martin, P. and C.A. Rogers (1995), Industrial location and public infrastructure. Journal of International Economics 39, 335-351.

Mikesell, J.L. (2000), Remote vendors and American sales and use taxation: The balance between fixing the problem and fixing the tax. National Tax Journal 53, 1273-1285.

Mintz, J. and H. Tulkens (1986), Commodity tax competition between member states of a federation: Equilibrium and efficiency. Journal of Public Economics 29, 133172.

Nam, C.W., R. Parsche and B. Schaden (2001), Measurement of value added tax evasion in selected EU countries on the basis of national accounts data. ifo Studien $47,127-144$.

OECD (2000), Revenue statistics 1965-1999. Paris.

Pflüger, M. (2001), Ecological dumping under monopolistic competition. Scandinavian Journal of Economics 103, 689-706.

Singh, N. and X. Vives (1984), Price and quantity competition in a differentiated duopoly. Rand Journal of Economics 15, 546-554.

Wilson, J.D. (1991), Tax competition with interregional differences in factor endowments. Regional Science and Urban Economics 21, 423-451. 